\title{
Reversible Luminescence Photoswitching of Colloidal CsPbBr3 Nanocrystals Hybridized with a Diarylethene Photoswitch
}

\section{(Supporting Information)}

Ashkan Mokhtar, Ryuki Morinaga, Yuji Akaishi, Manami Shimoyoshi, Sunnam Kim, Seiji Kurihara*, Tetsuya Kida*, Tuyoshi Fukaminato*

Department of Applied Chemistry \& Biochemistry, Graduate School of Science \& Technology, Kumamoto University, 2-39-1 Kurokami, Chuo-ku, Kumamoto 860-8555, Japan

*Author for correspondence and reprint requests;

E-mail address: tuyoshi@kumamoto-u.ac.jp (T. Fukaminato)

E-mail address: tetsuya@kumamoto-u.ac.jp (T. Kida)

E-mail address: kurihara@gpo.kumamoto-u.ac.jp (S. Kurihara) 


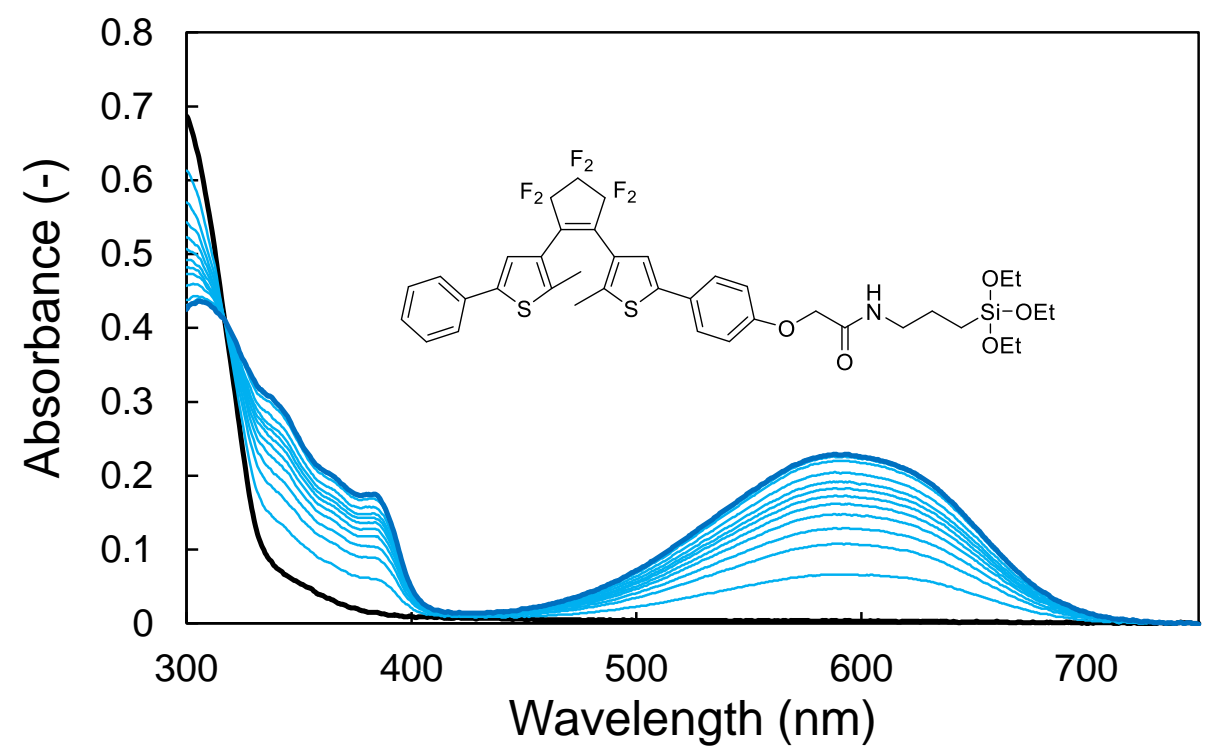

Figure S1. Absorption spectral change of the target DAE 1 upon irradiation with $365 \mathrm{~nm}$ UV light; the open-ring isomer (black-line) and PSS under irradiation with $365 \mathrm{~nm}$ light (thick blue-line).

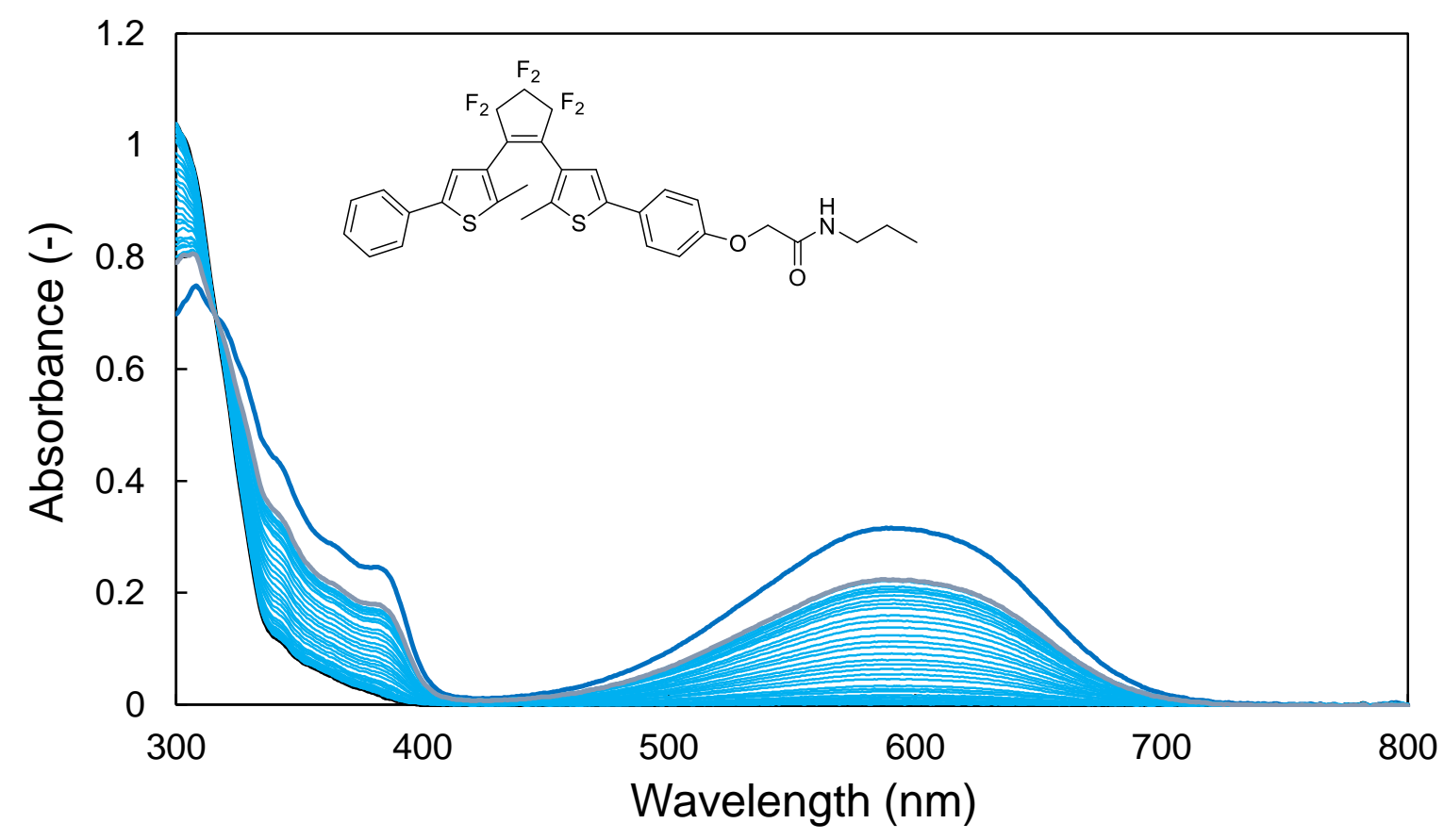

Figure S2. Absorption spectral change of the model DAE 2 upon irradiation with $365 \mathrm{~nm}$ UV light; the open-ring isomer (black-line), the pure close-ring isomer (thick blue-line) and PSS under irradiation with $365 \mathrm{~nm}$ light (gray-line). 
(a)

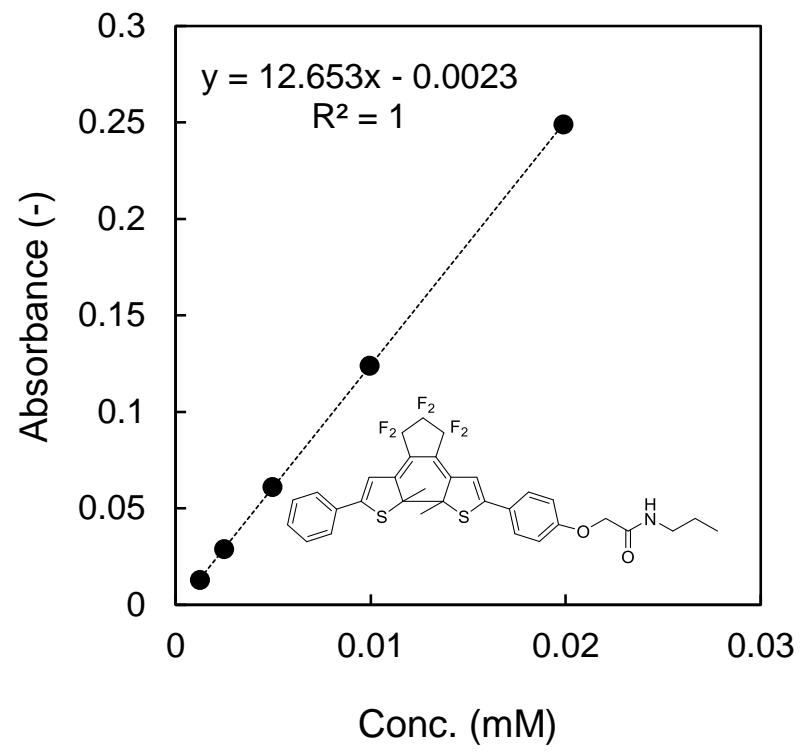

$\varepsilon=12653$

Conversion at $588 \mathrm{~nm}: 71 \%$ (b)

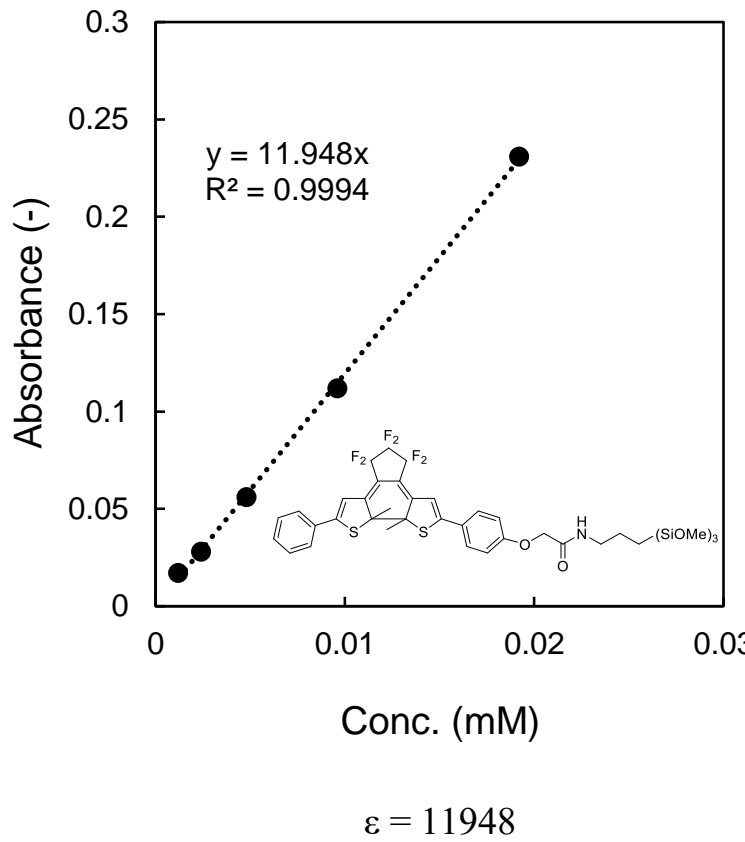

Estimated Conversion at 588 nm: 67\%

Figure S3. Plots of absorbance as the function of concentrations at PSS; (a) The model DAE 2 and (b) the target DAE 1.

(a)

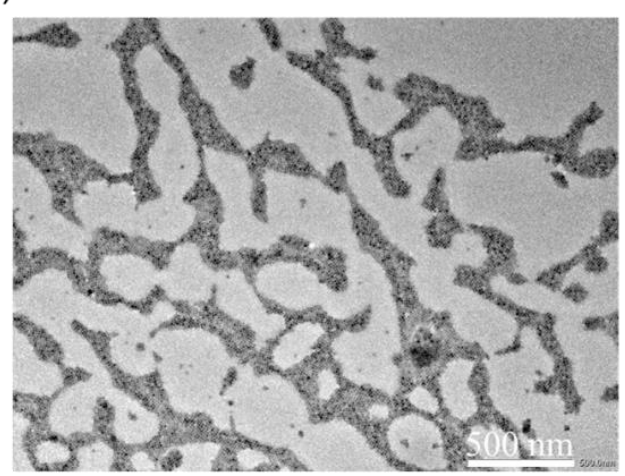

(c)

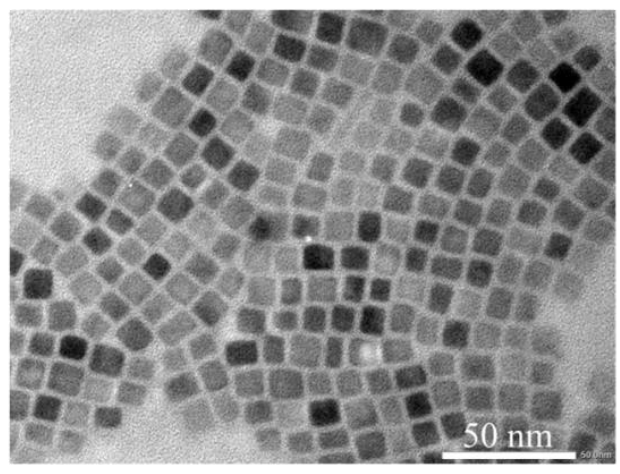

(b)

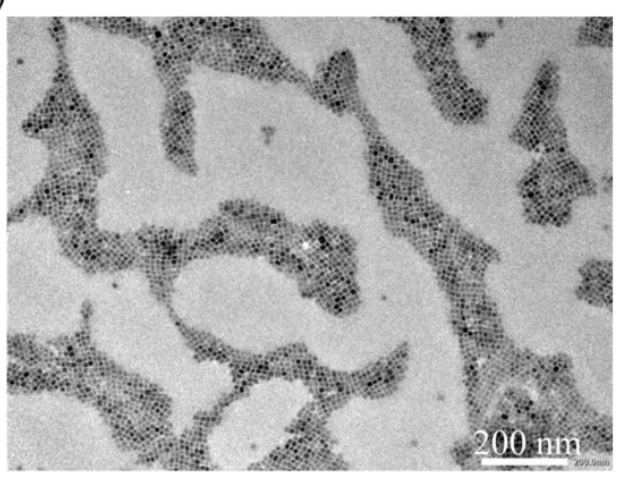

(d)

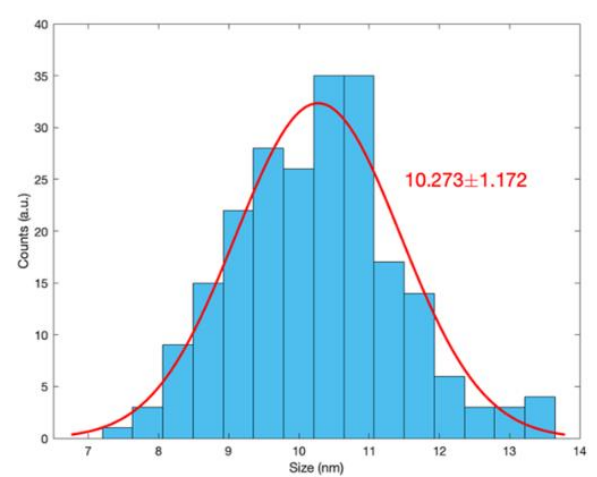

Figure S4. (a-c) TEM images with different magnification ratios and (d) size distribution histogram of the synthesized perovskite $\mathrm{CsPbBr}_{3}$ QDs based on particle size analysis of (c). 


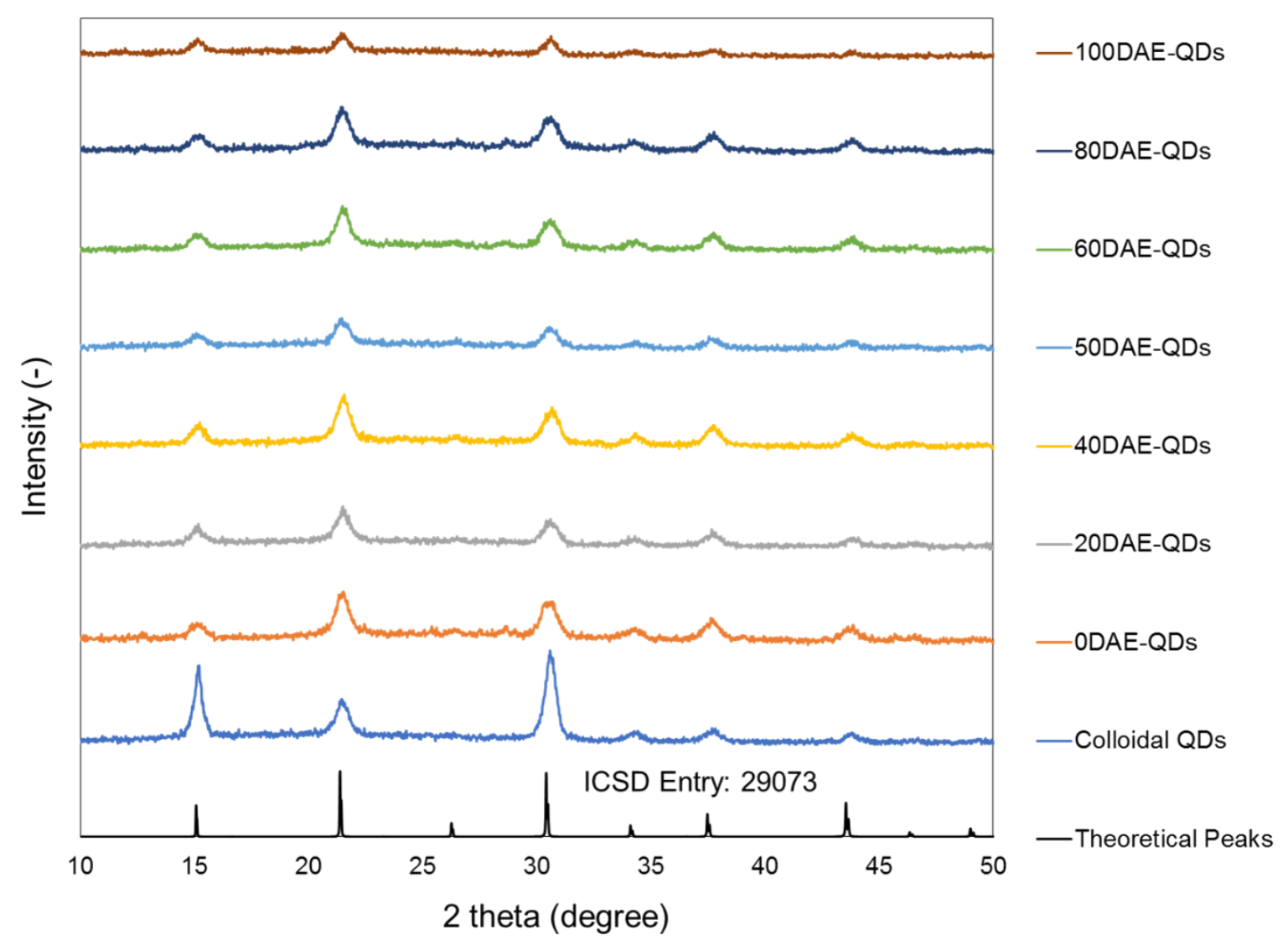

Figure S5. XRD diffraction patterns of colloidal QDs and each DAE-QDs hybrid.

Table S1. Composition of $1 \mathrm{~mL}$ of the coating solutions.

\begin{tabular}{cccc}
\hline Sample Name & $\begin{array}{c}\text { Coating Solution } \\
\text { Component Ratio } \\
\text { (APTES : DAE) }\end{array}$ & $\begin{array}{c}\text { 3-Aminotriethoxysilane } \\
\text { (APTES) }\end{array}$ & Diarylethene (DAE) $\mathbf{1}$ \\
\hline 0DAE-QDs & $10: 0$ & $21.28 \mu 1(0.10 \mathrm{mmol})$ & $0 \mathrm{mg}(0 \mathrm{mmol})$ \\
20DAE-QDs & $8: 2$ & $17.28 \mu 1(0.082 \mathrm{mmol})$ & $14.85 \mathrm{mg}(0.019 \mathrm{mmol})$ \\
40DAE-QDs & $6: 4$ & $12.96 \mu \mathrm{l}(0.062 \mathrm{mmol})$ & $29.80 \mathrm{mg}(0.037 \mathrm{mmol})$ \\
50DAE-QDs & $5: 5$ & $10.8 \mu 1(0.048 \mathrm{mmol})$ & $36.50 \mathrm{mg}(0.046 \mathrm{mmol})$ \\
60DAE-QDs & $4: 6$ & $8.64 \mu \mathrm{l}(0.041 \mathrm{mmol})$ & $43.80 \mathrm{mg}(0.055 \mathrm{mmol})$ \\
80DAE-QDs & $2: 8$ & $4.32 \mu \mathrm{l}(0.021 \mathrm{mmol})$ & $59.60 \mathrm{mg}(0.075 \mathrm{mmol})$ \\
100DAE-QDs & $0: 10$ & $0 \mu \mathrm{l}(0 \mathrm{mmol})$ & $73.40 \mathrm{mg}(0.092 \mathrm{mmol})$ \\
\hline
\end{tabular}




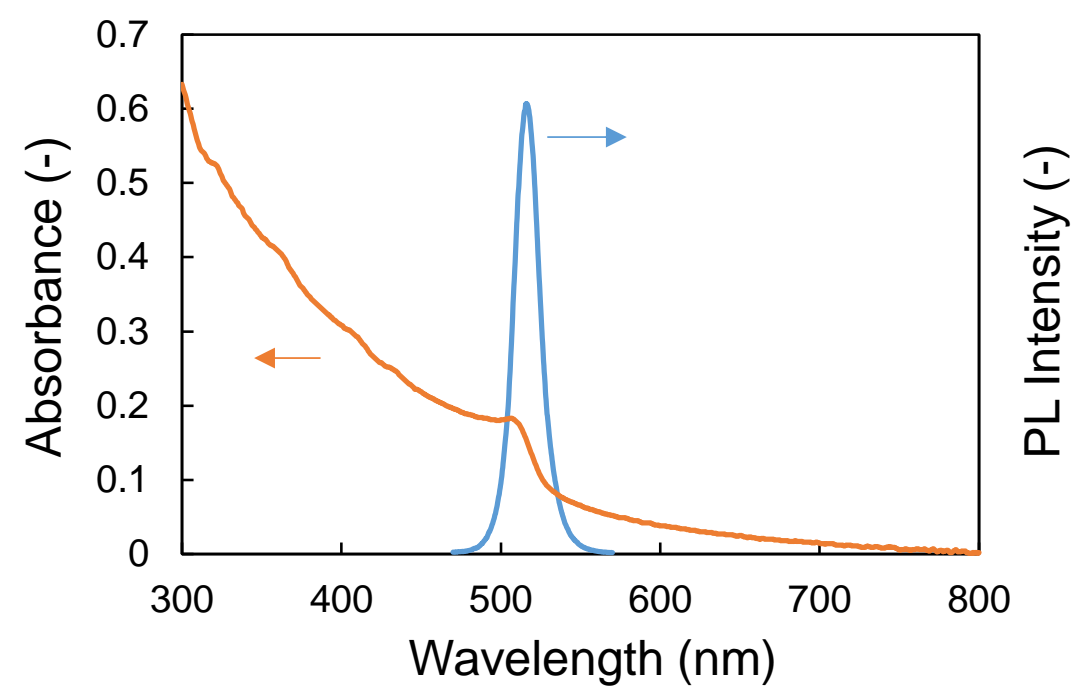

Figure S6. Absorption and PL spectra of the synthesized perovskite $\mathrm{CsPbBr}_{3}$ QDs.

(a)

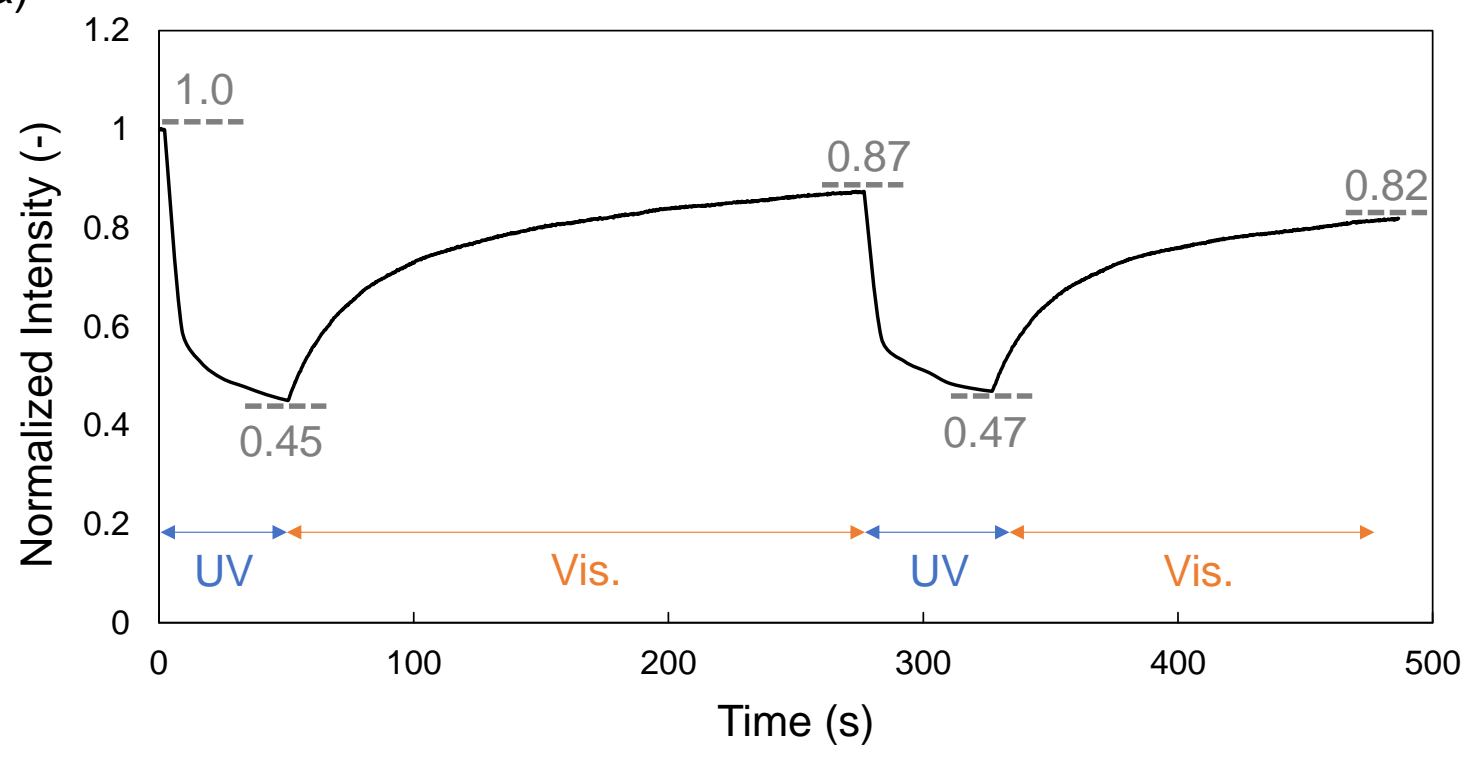

(b)

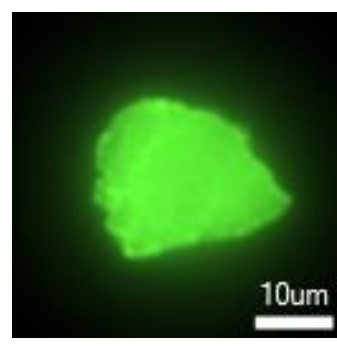

ON

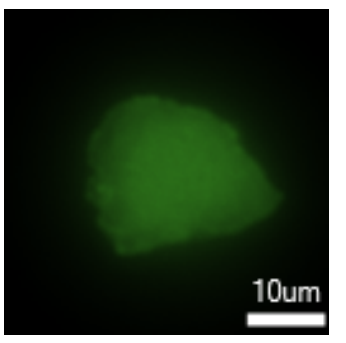

OFF

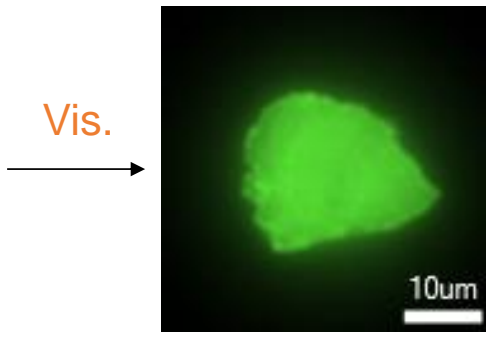

ON

Figure S7. PL switching behavior of a sample (60DAE-QDs) hybridized for $12 \mathrm{~h}$; (a) PL intensity trajectory upon alternate irradiation with UV and visible light (Maximum PL Quenching at $1^{\text {st }}$ cycle: $55 \%$, Recovery ( $1^{\text {st }}$ cycle): $\left.87 \%\right)$. (b) Luminescence microscopic images of PL photoswitching behavior of 60DAE-QDs hybrids embedded in PMMA film under excitation with $438 \mathrm{~nm}$ light $\left(150 \mu \mathrm{W} / \mathrm{cm}^{2}\right)$. 
Table S2. Elemental analysis of 60DAE-QDs hybrid based on XPS.

\begin{tabular}{ccccccccc}
\hline Element & $\mathrm{Cs}$ & $\mathrm{Pb}$ & $\mathrm{Br}$ & $\mathrm{C}$ & $\mathrm{N}$ & $\mathrm{O}$ & $\mathrm{F}$ & $\mathrm{Si}$ \\
\hline Composition (at \%) & 2.03 & 2.35 & 7.17 & 62.98 & 3.5 & 13.33 & 2.63 & 6.01 \\
\hline
\end{tabular}

The ratio of the DAEs in the silica matrix with respect to APTES can be calculated based on atomic ratios of silicon ( $\mathrm{Si}$ ) and fluorine $(\mathrm{F})$ measured by XPS which indicated that approximately $15 \%$ of the coating layer was consisted of DAEs.

(a)

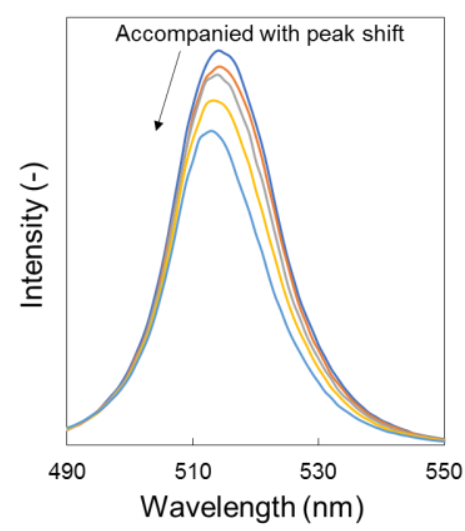

(d)

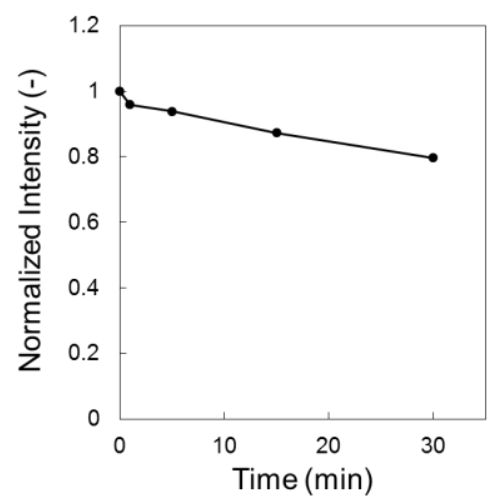

(b)

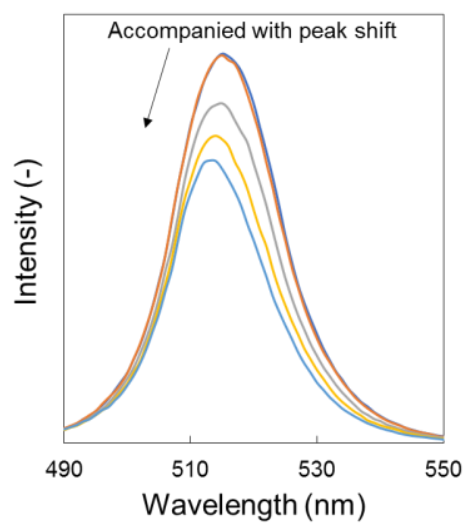

(e)

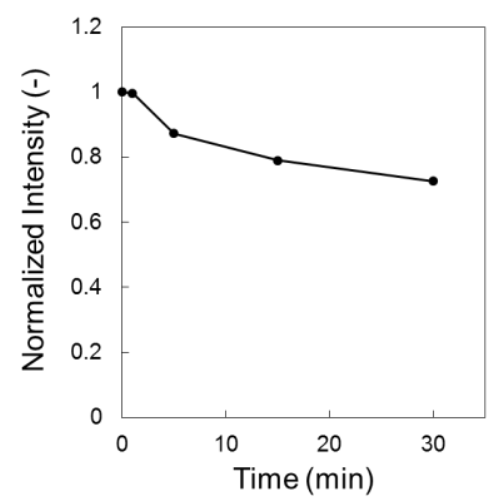

(c)

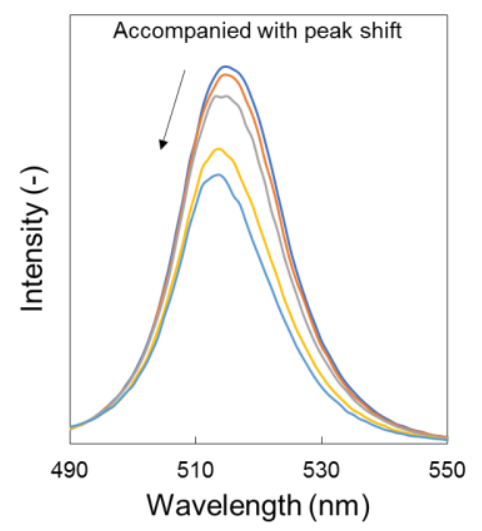

(f)

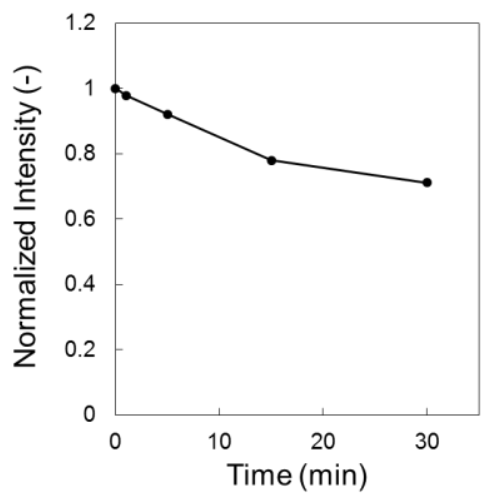

Figure S8. Stability of the synthesized perovskite $\mathrm{CsPbBr}_{3}$ QDs under different environments at dilute concentrations: (a, d) Stability of QDs in a dilute solution under irradiation with visible light (> 600 $\mathrm{nm}$ ) in toluene, (b, e) stability of QDs in a dilute solution under irradiation with visible light (> $600 \mathrm{~nm}$ ) in dry toluene and (c, f) stability of QDs in a dilute solution at dark in toluene*.

*The synthesized QDs (dispersed in $5 \mathrm{~mL}$ toluene) were approximately diluted 100 fold and then subjected to irradiation of light and analysis. 
(a)

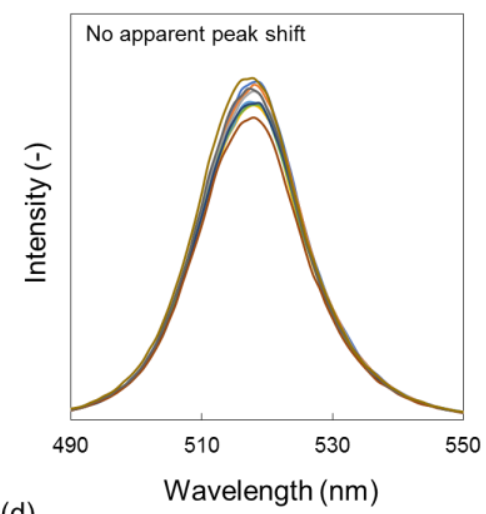

(d)

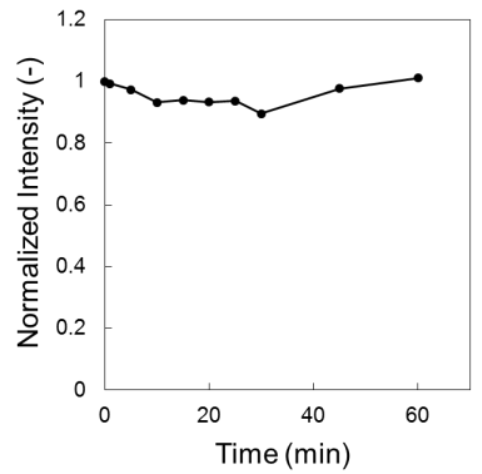

(b)

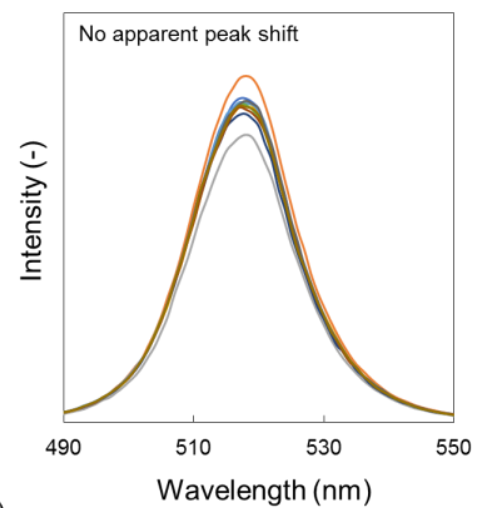

(e)

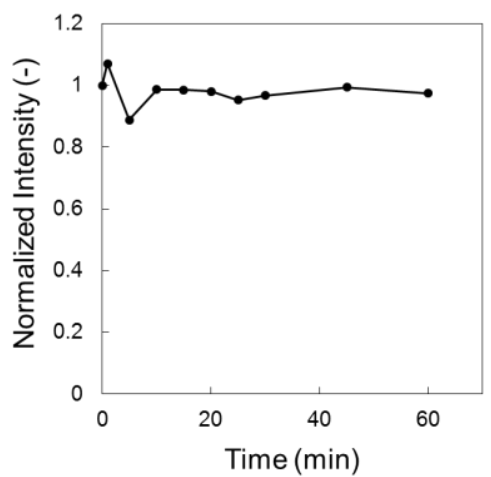

(c)

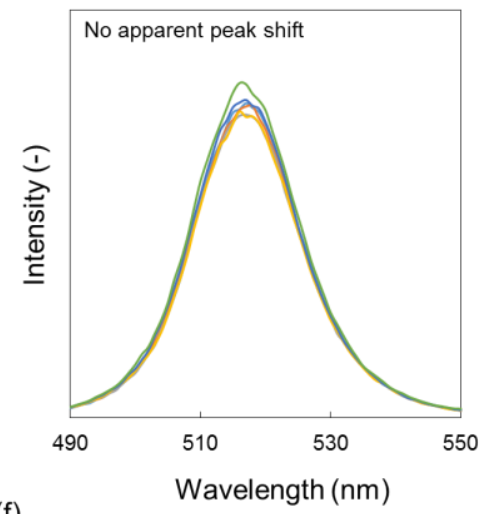

(f)

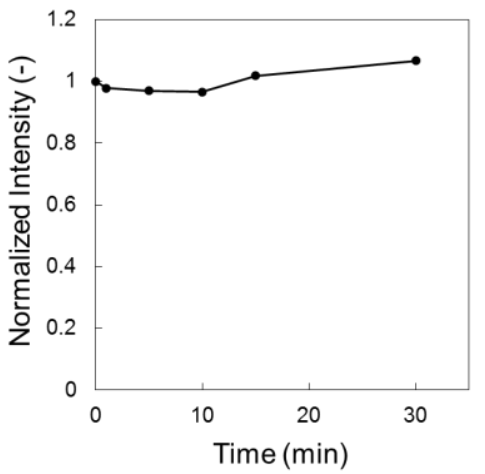

Figure S9. Stability of the synthesized perovskite $\mathrm{CsPbBr}_{3}$ QDs under different environments at concentrated solutions: (a, d) Stability of QDs in a concentrated solution under irradiation with UV light $(365 \mathrm{~nm})$ in toluene, $(\mathrm{b}, \mathrm{e})$ stability of QDs in a concentrated solution under irradiation with visible light $(>600 \mathrm{~nm})$ in toluene and (c, f) stability of QDs in a concentrated solution (necessary concentration for hybridization reaction) at dark in toluene*.

*The synthesized QDs (dispersed in $5 \mathrm{~mL}$ toluene) were subjected to each test and a fraction of each sample was approximately diluted 100 fold immediately before analysis.

(a)

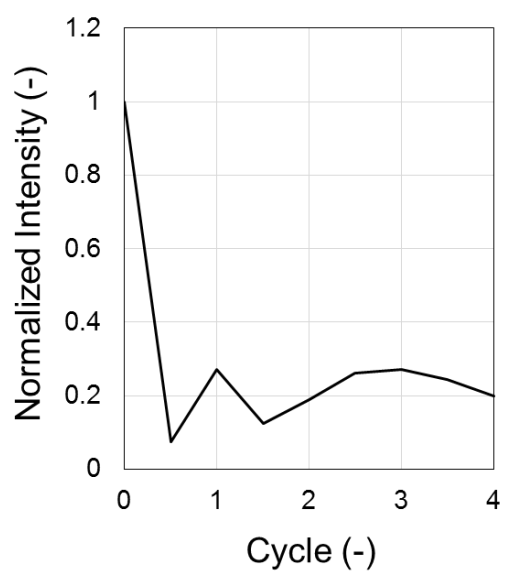

(b)

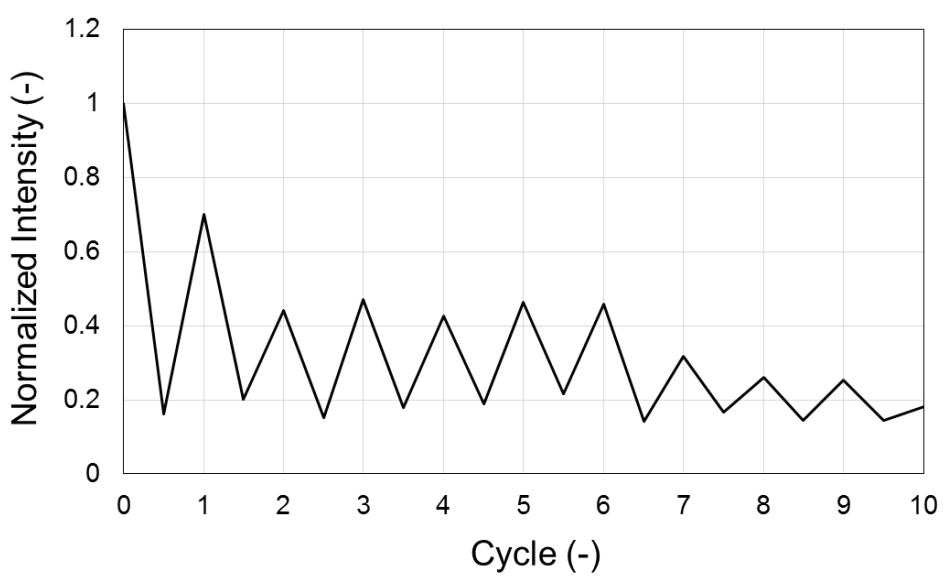

Figure S10. PL switching cycles comparison of two different hybrids upon alternate irradiation of UV $(365 \mathrm{~nm})$ and visible light $(561 \mathrm{~nm})$ in dilute dispersions: (a) PL switching cycles of a dilute dispersion of 80DAE-QDs and (b) PL switching cycles of a dilute dispersion of 60DAE-QDs. 


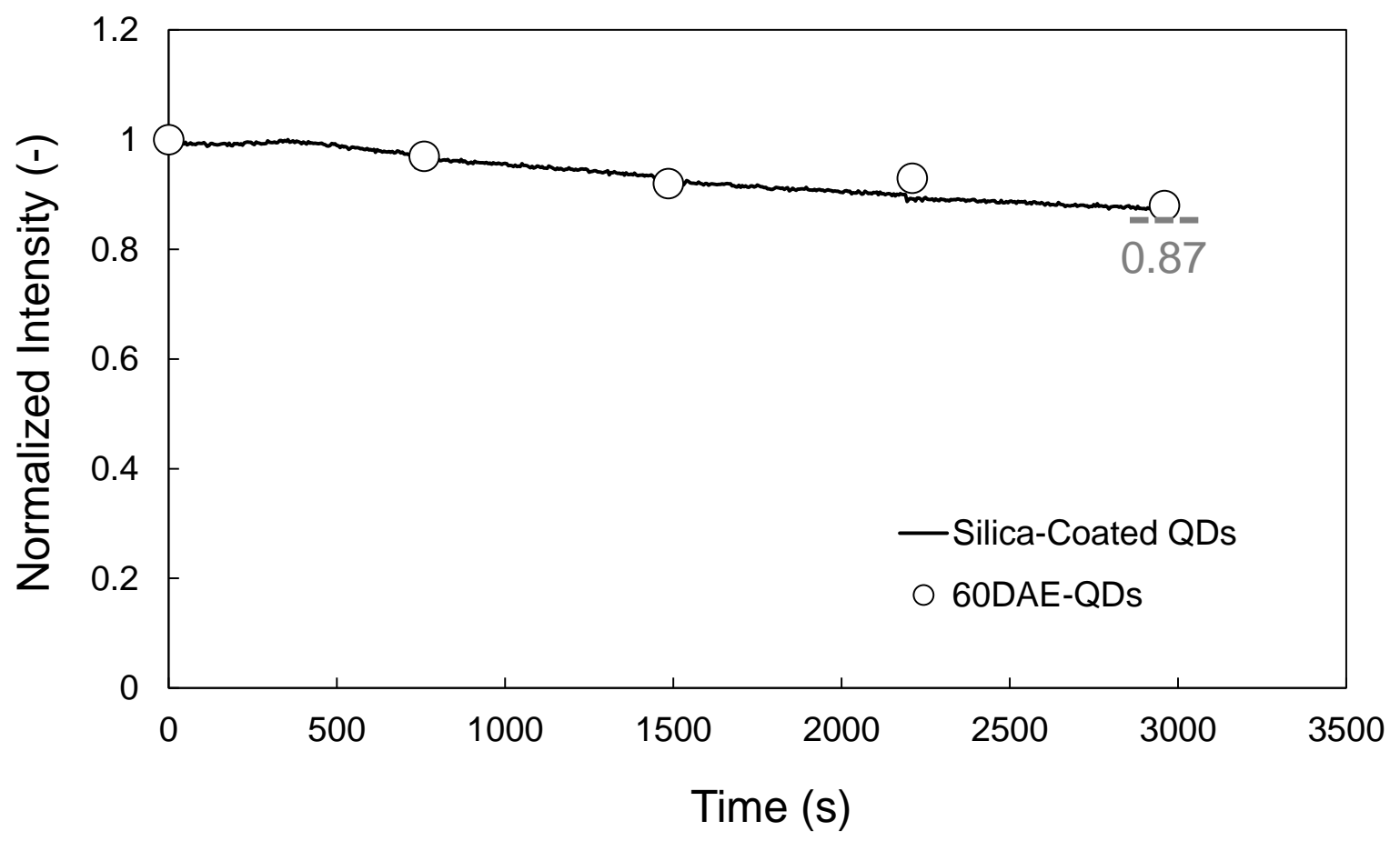

Figure S11. Photostability of silica coated QDs with no DAE in the coat layer; changes in PL intensity in solid thin film under irradiation of light. 